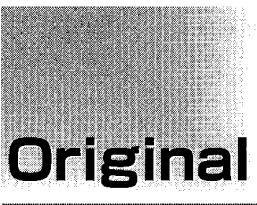

Received July 8, 2005

Revision accepted

Nov. 4, 2005

Code No. 522

\title{
Physical Imaging Properties and Low-contrast Performance of a Newly Developed Flat-panel Digital Radiographic System
}

\author{
MASAO MATSUMOTO, TATSUYA YAMAZAKI,1) MAKOTO NOKITA,1) \\ SHINSUKE HAYASHIDA, ${ }^{1)}$ AKIRA YOSHIDA, ${ }^{2)}$ \\ TADAMITSU IDEGUCHI, ${ }^{3)}$ KAZUHIKO HIMURO, \\ MASAFUMI OHKI,') SEIJI KUMAZAWA,") and YOSHIHARU HIGASHIDA ${ }^{5)}$ \\ Division of Health Science, Graduate School of Medicine, Osaka University \\ 1) DR System Development Division, Canon Inc. \\ 2)Department of Radiological Sciences. Hiroshima Prefectural College of Health Science \\ 3) Department of Radiology. National Kyushu Medical Center \\ 4)Department of Radiology, Kyushu University Hospital \\ 5)Department of Health Science, School of Medicine, Kyushu University
}

\section{Introduction}

In many areas of clinical practice, the use of digital radiography systems based on a flat-panel detector (FPD) fabricated from hydrogenated amorphous silicon (a-Si:H) has become increasingly popular in recent years. There are currently two main types of FPD: direct and indirect. Imaging properties of these two different types of FPD have been measured and reported by various investigators. ${ }^{1-10}$ ) The main difference between the two types is the conversion process. For direct $\mathrm{x}$-ray detectors, a photoconductive layer (amorphous selenium: a$\mathrm{Se}$ ) converts the $\mathrm{x}$-ray energy to electric charges that are directed to the collecting pixel capacitors by an electric field. For indirect detectors, which are more common, a scintillation phosphor layer converts the energy of $x-$ ray photons to visible light photons that are subsequently detected by the pixel photodiodes. These visible light photons are stored in the form of electronic charges in the capacitors associated with each pixel until readout.

There are also two types of indirect FPD, according to the phosphor screens that they employ. In one type, rare-earth phosphor materials $\left(\mathrm{Gd}_{2} \mathrm{O}_{2} \mathrm{~S}: \mathrm{Tb}^{3+}\right)$ are used in a layer of binding material. ${ }^{1,5,7)}$ This type of FPD was first introduced and has been widely used as a clinically acceptable digital imaging system in various radiographic examinations. In the other type, thallium-doped cesium iodide ( $\mathrm{CsI}: \mathrm{Tl})$ grown in columnar structures is used as a phosphor material.

Recently, Samei et al. ${ }^{10,11)}$ reported a comparative assessment of imaging properties of two indirect-type FPDs by measuring modulation transfer function(MTF), noise power spectrum (NPS), and detective quantum

\section{Summary}

We investigated the clinical usefulness of a newly developed flat-panel detector(FPD) system by comparing its physical imaging properties and low-contrast detectability with those of a current FPD system. The newly developed CsI-based indirect FPD (Canon, CXDI-40C) and current $\mathrm{Gd}_{2} \mathrm{O}_{2} \mathrm{~S}$-based FPD (Canon CXDI-11) systems were used. Characteristic curves, resolution properties, radiographic noise, detective quantum efficiencies (DQEs) and low-contrast detectability for both systems were measured. The new FPD system showed considerably lower noise levels than those of the current FPD system. DQE $(0) \mathrm{s}$ of the new and current FPD systems were $75 \%$ and $35 \%$, respectively. Observer performance tests of the contrast-detail (C-D) phantom indicated that the new FPD system can significantly improve low-contrast performance over that obtainable with the current FPD system under the same conditions of exposure. The new FPD system provided approximately $50 \%$ reduction in exposure while providing comparable detectability. The newly developed FPD system provides radiographic images with excellent inherent physical image quality and low-contrast performance.

Key words: Flat-panel detector (FPD), Physical imaging property, Low-contrast performance, Contrast-detail (C-D) phantom, Digital radiography system 
efficiency (DQE) using identical methodologies. The results indicated that the CsI-based detector demonstrated a significantly higher DQE compared with that of a $\mathrm{Gd}_{2} \mathrm{O}_{2} \mathrm{~S}$-based detector, but no one has compared the difference in low-contrast detectability of a CsI-based detector and a $\mathrm{Gd}_{2} \mathrm{O}_{2} \mathrm{~S}$-based detector.

Our aim in this study was to investigate the imaging properties and possibility of dose reduction of a newly developed CsI-based detector by evaluating its basic imaging properties and low-contrast detectability, and by comparing them with that of current indirect $\mathrm{Gd}_{2} \mathrm{O}_{2} \mathrm{~S}$ based FPD. ${ }^{12,13)}$ The imaging performances of two indirect FPDs were assessed in terms of the digital characteristic curves, pre-sampling MTF, digital Wiener spectra (WS), and DQE. We also performed a comparison of low-contrast detectability of a contrast-detail (C-D) phantom between the new and current FPD systems.

\section{Materials and Methods}

\section{1-1 Description of detectors}

The specifications of new and current FPDs are shown in the Table. ${ }^{12)}$ The new FPD (Canon, CXDI-40C) consists of a CsI:TI scintillator coupled with a $43 \mathrm{~cm} \times 43$ $\mathrm{cm}$ amorphous silicon thin-film transistor array with a $160 \mu \mathrm{m}$ pixel pitch. Figure 1 shows an overview of the new FPD unit (a) and microphotograph of the CsI:Tl scintillator (b). Since the scintillator has a needle-like (columnar) structure and can transmit fluorescent light without spreading, it can simultaneously satisfy an increase of $\mathrm{x}$-ray absorption and maintain its resolution properties. The current FPD (Canon, CXDI-11) consists of a phosphor screen $\left(\mathrm{Gd}_{2} \mathrm{O}_{2} \mathrm{~S}: \mathrm{Tb}^{3+}\right)$ coupled with a $43 \mathrm{~cm} \times$ $43 \mathrm{~cm}$ amorphous silicon thin-film transistor array with identical pixel pitch.

\section{1-2 Measurement of fundamental physical imaging properties}

We measured and evaluated digital characteristic curves, pre-sampling MTF, digital WS, and DQE for the new and current FPD systems based on IEC62220-1. ${ }^{14)}$ We obtained linear original images, which were preprocessed with offset and gain corrections, as shown in Fig. 2 , to neglect the post-processing effects.

Digital characteristic curves were measured by the time scale method, which changed $\mathrm{mAs}$ values at tube voltage $80 \mathrm{kV}$ with an added $20 \mathrm{~mm} \mathrm{Al} \mathrm{filtered} \mathrm{x-ray}$ tube. The beam quality was chosen so as to use the traditional common BRH canonical beam quality ${ }^{15)}$ and to
Table Specifications of new and current FPD systems.

\begin{tabular}{|c|c|c|}
\hline & new $(C X D I-40 C)$ & current (CXDI-11) \\
\hline sensor type & \multicolumn{2}{|c|}{ scintillator and a-Si photoconverter } \\
\hline scintillator & Csl:TI & $\mathrm{Gd}_{2} \mathrm{O}_{2} \mathrm{~S}: \mathrm{Tb}^{3+}$ \\
\hline effective area & $43 \mathrm{~cm} \times 43 \mathrm{~cm}$ & $43 \mathrm{~cm} \times 43 \mathrm{~cm}$ \\
\hline matrix size & \multicolumn{2}{|c|}{$2,688 \times 2,688(7.2 \mathrm{M}$ pixels $)$} \\
\hline pixel size & \multicolumn{2}{|c|}{$160 \mu \mathrm{m} \times 160 \mu \mathrm{m}$} \\
\hline$A / D$ converter & 1,638 (14bit) & $1,638(14 \mathrm{bit})$ \\
\hline gray levels & 4,096 (12bit) & 4,096 (12bit) \\
\hline
\end{tabular}

nearly satisfy IEC62220-1 beam quality. Focus-FPD distance was $3.6 \mathrm{~m}$.

The resolution properties of the new and current FPD systems were evaluated by measuring MTF. To obtain the inherent resolution property in the new and current FPD systems, pre-sampling $\operatorname{MTF}(\operatorname{MTF}(q, u, v))$, which includes the unsharpness of scintillator and the unsharpness of the sampling aperture, was obtained by a two-dimensional Fourier transformation of the edge images. ${ }^{13,14,16-19)}$ In the radiography of edge images, we used a conventional x-ray unit (AUD150G, SHIMADZU, Kyoto, Japan). A slightly angulated tungsten alloy edge (usually less than $3^{\circ}$ ) of $100 \mathrm{~mm} \times 100 \mathrm{~mm} \times 1 \mathrm{~mm}$ was used to obtain the edge image at different alignments between the center of the edge and the sampling coordinate, ${ }^{13)}$ as shown in Fig. 3. To eliminate geometric unsharpness, the edge was placed directly at the center of the FPD surface. The exposure technique of $80 \mathrm{kV}$ was used with an added $20 \mathrm{~mm}$ Al filtered $\mathrm{x}$-ray tube. The distance between the focal spot and FPD was 3.6 m. A characteristic curve, which relates the output pixel value to the input relative $\mathrm{x}$-ray intensity, was used as a means of linearization.

The physical properties of radiographic noise for the new and current FPD systems were quantified by means of the WS. The WS $(W S(q, u, v))$ was obtained using the fast Fourier transform (FFT) of a two-dimensional noise pattern of a uniform exposure image obtained at $80 \mathrm{kV}$. Incident exposure was accurately measured by using an ionization chamber mounted in a fixed position between the focal spot and the FPD. The measured $W S(q, u, v)$, in terms of pixel value, were converted to those in terms of relative $x$-ray intensity by using the characteristic curve of the system.

$N E Q(q, u, v)$ were calculated from measured $M T F$ $(q, u, v)$ and $W S(q, u, v)$ by the following equation: 


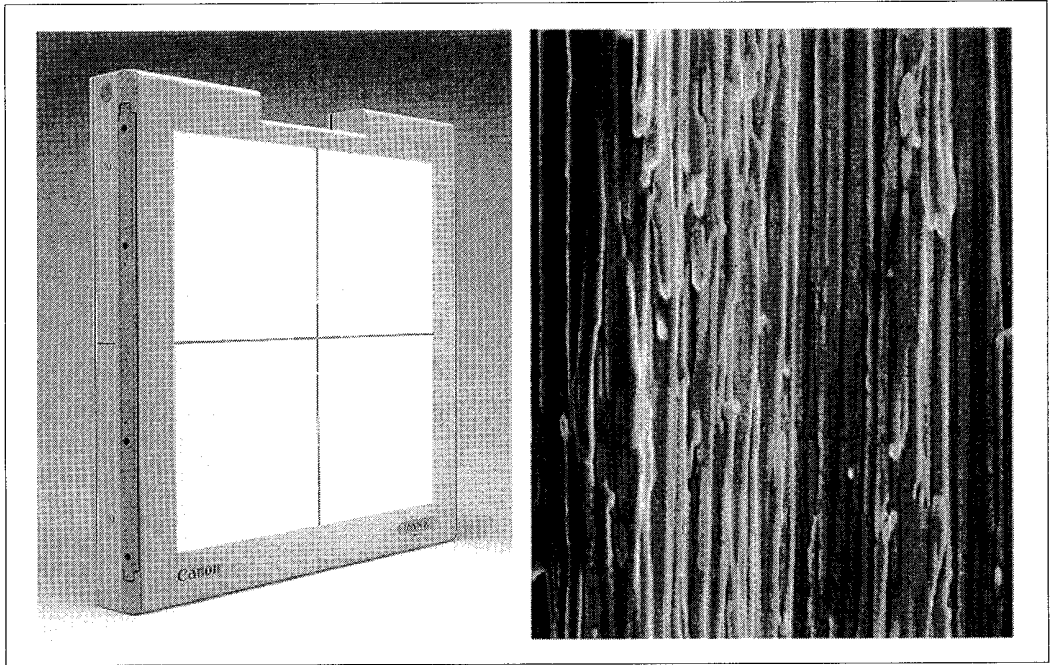

Fig. 1 Overview of (a)the new FPD (CXDI-40C) and (b) a microphotograph of the CsI:TI scintillator (SEM: scanning electron a $\quad b$ microscope, $\times 1000$ ).

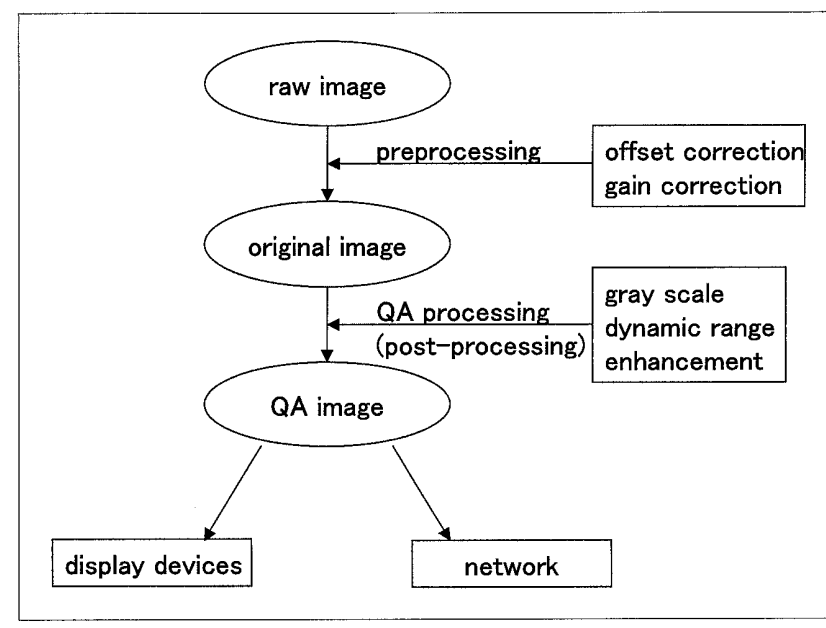

Fig. 2 Linear original imaging preprocess with offset and gain correction except for the post-processing effects.

$$
\operatorname{NEQ}(q, u, v)=\operatorname{MTF}(q, u, v) / W S(q, u, v),
$$

where both $u$ and $v$ are spatial frequencies in the horizontal and vertical directions, respectively. $D Q E(q, u, v)$ were calculated from measured $q$ and $N E Q$ $(q, u, v)$ by the following equation:

$$
\begin{aligned}
& D O Q(q, u, v)=N E Q(q, u, v) / q, \\
& q=\left(\int E \cdot \phi(E) d E\right)^{2} / \int E^{2} \cdot \phi(E) d E,
\end{aligned}
$$

where $q$ is the equivalent number $\left(2.59 \times 10^{5}\right.$ counts/ $\mathrm{mR} / \mathrm{mm}^{2}$ ) of photons, $\phi(E)$ is photon spectrum (Fig. 4), and $E$ is photon energy.

Photon spectrum and exposure were directly measured using a high-resolution Schottky CdTe detector

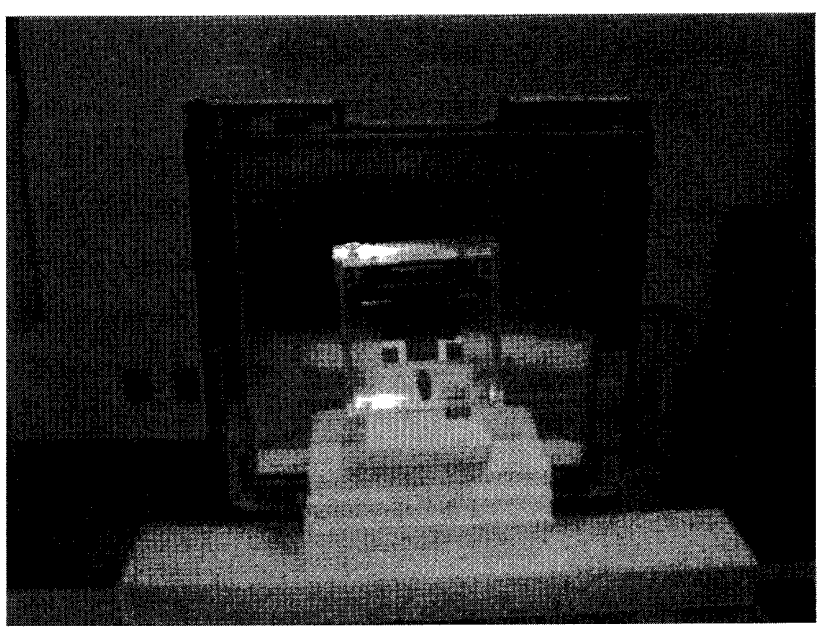

Fig. 3 Experimental set-up of the tungsten edge for measurement of MTFs.

(Toyo Medic, Ramtec 413) 20,21) and an ionization chamber (Radcal Model 9015)with 180 cc chamber(Radcal, Model 10×5-180) on the same geometry of measurement of $\operatorname{MTF}(q, u, v)$ and $W S(q, u, v)$, and $q$ was calculated from these photon spectra and exposure.

\section{1-3 Measurement of low-contrast detectability}

A C-D phantom (Kyoto Kagaku, Kyoto, Japan)was used to compare the detection capabilities of the new and current FPD systems. The C-D phantom consists of a $10 \mathrm{~mm}$ acrylic plate containing a $15 \times 15$ array, in which circular holes of various depths and diameters were milled to create objects of various contrasts and sizes. ${ }^{9,22)}$ These depths and diameters ranged from $0.3-8.0 \mathrm{~mm}$, with 15 
steps increasing logarithmically. For $4 \mathrm{~mm}$ and smaller objects, an additional object was created and placed randomly at one of the four corners. These additional objects were used to help minimize potential bias due to a priori knowledge of the presence of objects in each square region.

To simulate chest radiography, a C-D phantom was exposed together with an $8 \mathrm{~cm}$ thick acrylic phantom. To compare the effect of incident exposure on detectability, we varied incident $\mathrm{x}$-ray exposure by changing the exposure time. Incident exposure that yields a radiographic density of 1.20 with a medium-speed screenfilm system (Fuji Film, HG-M2/UR-2) was defined as the relative incident exposure of 1 . Relative exposure to the detector was varied from 2 to $1 / 3(\times 2, \times 1, \times 1 / 2, \times 1 / 3)$. For each combination of relative incident exposure level, three image samples were produced for all exposure conditions. The distance between the focal spot and the detector was $200 \mathrm{~cm}$, and the field size at the detector surface was $30 \mathrm{~cm} \times 30 \mathrm{~cm}$. A tube voltage of $120 \mathrm{kV}$ was employed for exposure conditions. An anti-scatter grid with 40 lines/cm, and 10-to-1 ratio was used. All C-D phantom images were printed on a single emulsion film. In this study, we did not use an image processing technique such as contrast enhancement or spatial frequency enhancement, because the purpose of the study was to compare the detectability of a low-contrast object between new and current FPD systems. Therefore, the radiographic contrast of all test images produced by FPD systems were matched to those of the screen-film systems.

C-D phantom images were presented to observers. Each observer selected the lowest contrast pattern of each size that was detectable with a 50\% confidence level. Observers were allowed to choose a suitable viewing distance and observation time as they wished. The resulting average for each system was used as an evaluation value of threshold disk thickness. Observers included 13 readers $(6$ medical physicists and 7 students of medical sciences courses). Prior to the experiments, the observers were familiarized with the types of images to be viewed and were trained in the experimental procedure to be used, with emphasis on identifying the possible object regions. To evaluate overall detection performance, average $\mathrm{C}$ D curves were calculated from individual reading data. ${ }^{23)}$

\section{Results}

Figure 5 shows a comparison of the digital charac-

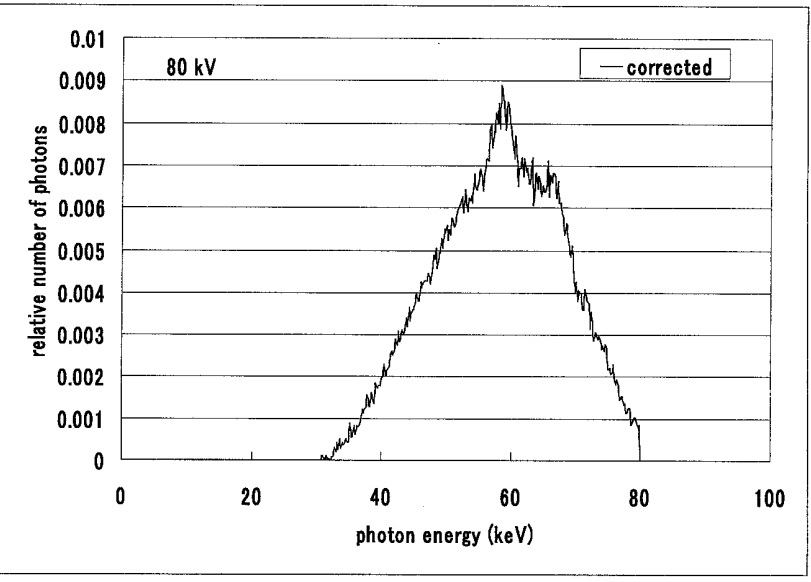

Fig. 4 Relative photon spectrum measured with added 20 $\mathrm{mm} \mathrm{Al}$ filter and $0.1 \mathrm{~mm} \phi \mathrm{W}$-pinhole collimator (FDD=3.6 m, $80 \mathrm{kV}, 320 \mathrm{~mA}, 10 \mathrm{~s}$ ).

teristic curves for the new FPD and current FPD systems. Both systems showed sufficient linearity over the range of radiographic exposure. Since the amorphous silicon thin-film transistor array and peripheral circuit including gain settings, amplifiers, and analog-to-digital (A/D) converters are different between the new FPD and current FPD systems, absolute output in A/D unit per unit exposure is not a useful index. Therefore Fig. 5 presents only the linearity characteristics.

Figure 6 shows a comparison of the pre-sampling MTFs for the new and current FPD systems. At all frequencies, the MTF for the new system was comparable to or slightly greater than that for the current system, even though there is a difference in scintillator materials. This is due to the design and fabrication of the scintillator including thickness, column diameter, and other deposition conditions. Since there were no differences in pre-sampling MTFs, digital WS, and DQEs between the horizontal and vertical directions, properties in the horizontal direction are shown.

Figure 7 shows a comparison of the digital WS for the new and current FPD systems measured at different incident exposure levels. Both WS decrease according to the increase in exposure. The WS of the new FPD system (a) is significantly lower, which means the noise is less, than that of the current FPD system (b) when compared with the same exposure.

Figure 8 shows a comparison of the DQEs for the new FPD and current FPD systems obtained under the same exposure conditions $\left(\sim 0.3 \mathrm{mR}: 8 \times 10^{-8} \mathrm{C} / \mathrm{kg}\right)$. The DQE of the new FPD system exhibited almost twice as much as that of the current FPD system at every spatial 


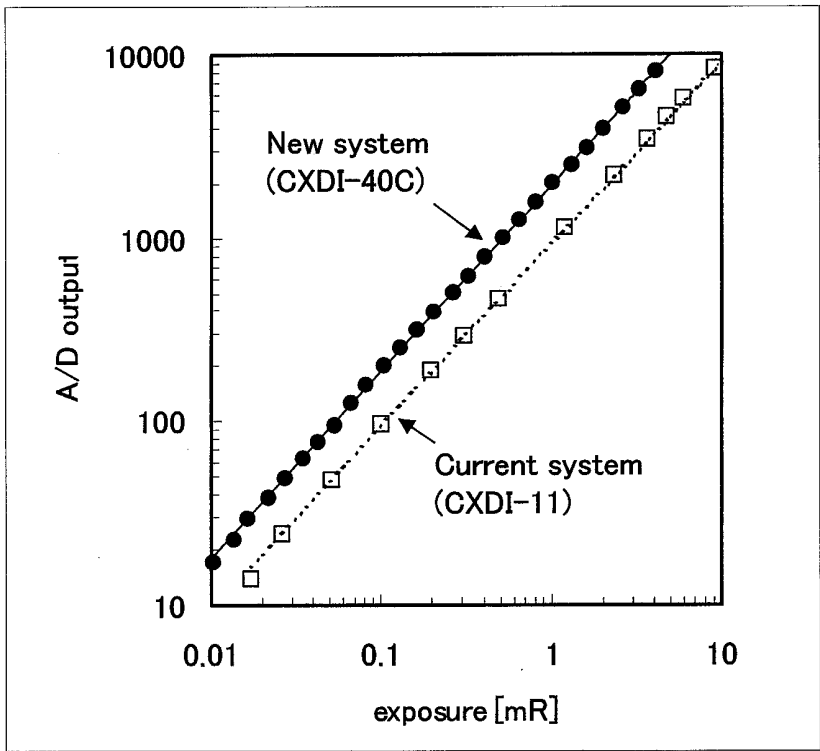

Fig. 5 Comparison of digital characteristic curves for the new FPD (CXDI-40C) and current FPD (CXDI-11) systems.

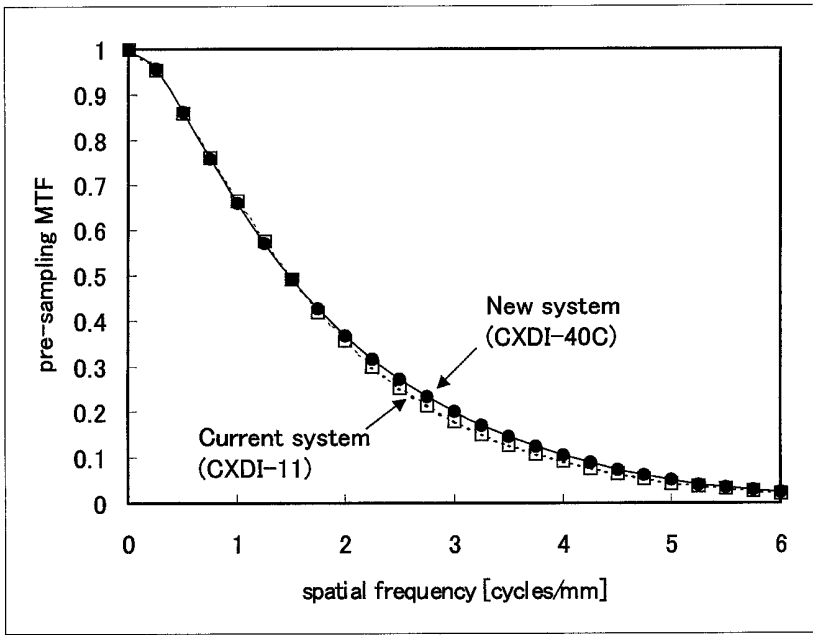

Fig. 6 Comparison of pre-sampling MTFs for the new and current systems. Since there were no differences in pre-sampling MTF in horizontal and vertical directions, properties in the horizontal direction are shown.
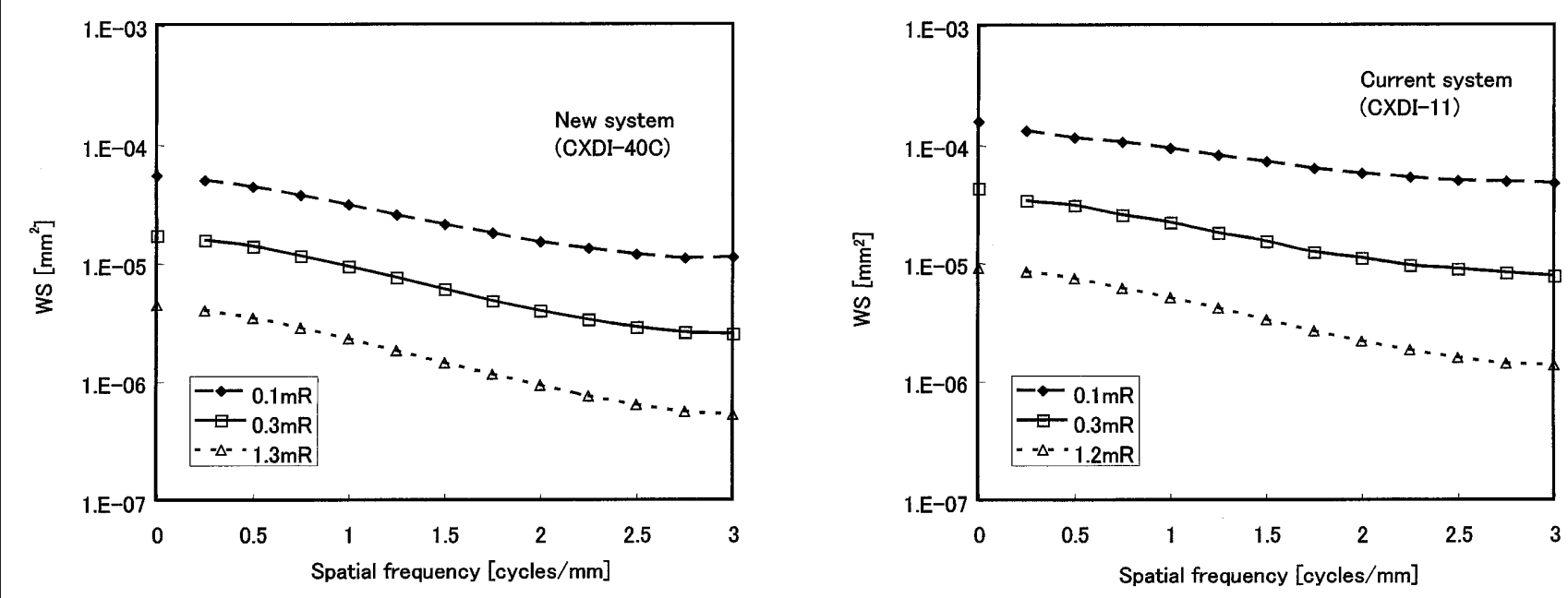

Fig. 7 Comparison of digital WS for the new (a) and current (b) FPD systems, obtained with various exposure conditions. Since there were no differences in digital WS in the horizontal and vertical directions, properties in $a \mid b$ the horizontal direction are shown. According to IEC62220-1, digital WS that is just below the Nyquist frequency ( 3.125 cycles $/ \mathrm{mm}$ ) is shown.

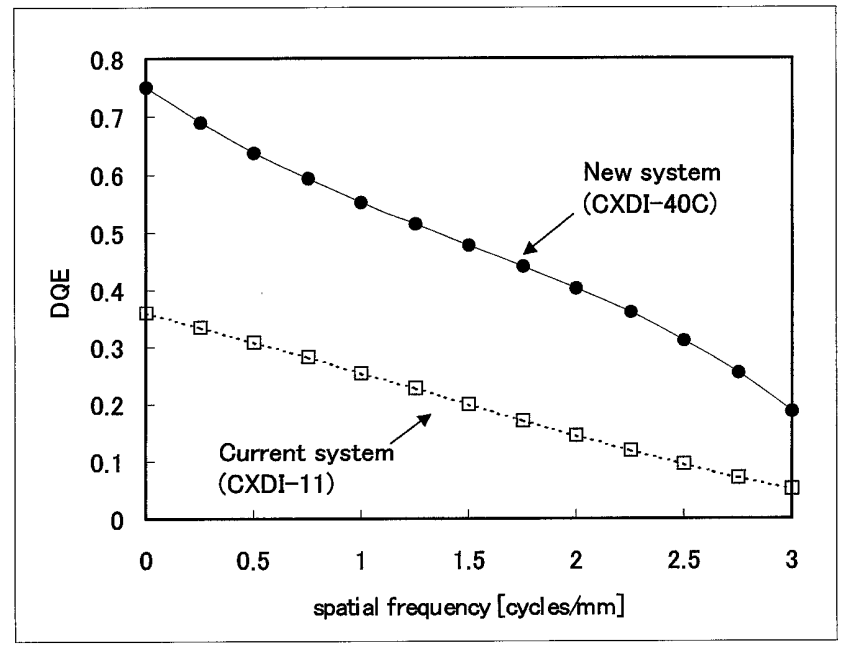

Fig. 8 Comparison of DQEs for the new and current FPD systems. Since there were no differences in DQE in the horizontal and vertical directions, properties in the horizontal direction are shown. According to IEC62220-1, DQE that is just below the Nyquist frequency $(3.125$ cycles $/ \mathrm{mm}$ ) is shown. 
frequency. This is mainly accomplished by the difference of $\mathrm{x}$-ray absorption in the scintillator. Since CsI: Tl has a needle-like structure and it can transmit the fluorescent light to the output surface without spreading like an optical fiber, it can increase the thickness to absorb more $\mathrm{x}$-rays without compromising the resolution properties. This is one of the advantages of the CsI:Tl over other scintillators in that it can reduce the dosage.

In Fig. 9, new (a) and current (b) FPD images of the C-D phantom acquired with the same incident exposures are shown. The circular holes of various depths and diameters are not depicted clearly on the current system.

Figure 10 shows enlarged portions of C-D phantom images and demonstrates the difference in image quality between the two systems. The relative incident exposures to the upper and lower images for new (a) and current (b) detectors were 1 and 0.5 , respectively. It is apparent that the radiographs of the new system show the low-contrast signals more clearly than do those of the current system.

Figure 11 indicates the C-D curves obtained with the new (a) and current (b) systems at various incident exposure levels. It is apparent that the minimum detectable object contrast increases with decreasing incident exposure for both systems. However, over the entire range of diameters, the threshold contrast of the new system demonstrates lower levels than those of the current system when compared at comparable levels of incident exposure.

In order to facilitate the comparison of threshold contrast for new and current systems, only two kinds of C-D curves with relative exposures of 1 and $1 / 2$ for both systems are plotted in Fig. 12. This figure shows that the new system can improve threshold contrast over that obtainable with the current system under the same exposure level. It can be seen from Fig. 11 that the curve for the new system, obtained with an incident exposure of $1 / 2$, and the current system curve, with the relative
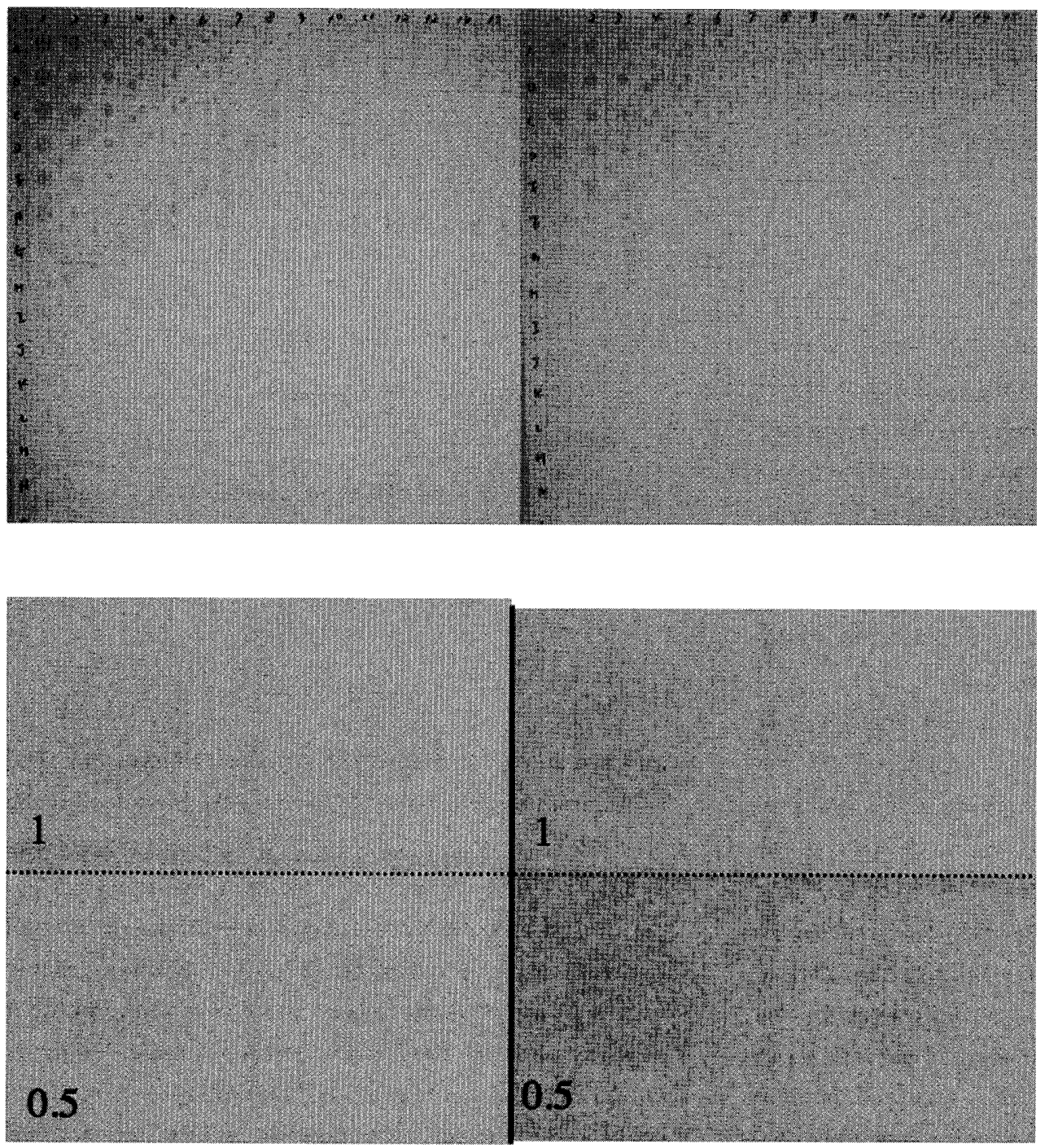

a b

Fig. 9 Comparison of C-D phantom images used for evaluation of the detection task obtained with the new and current FPD systems. The incident exposures to the new and current detectors in (a) and (b) were the same.

b

Fig. 10 Comparison of enlarged portions of $\mathrm{C}-\mathrm{D}$ phantom images. New (left upper and lower images) and current (right upper and lower images) FPD images are shown. The relative incident exposures to the upper and lower images for new and current detectors were 1 and 0.5, respectively. 

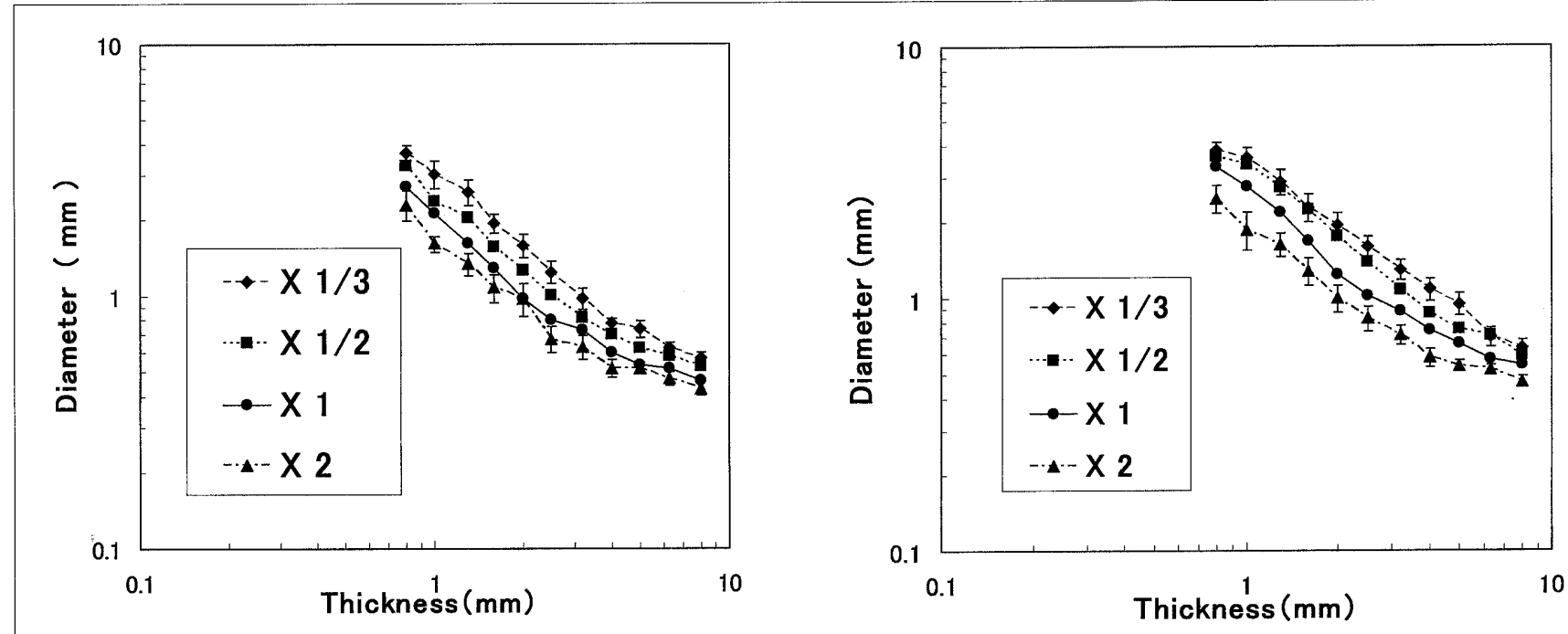

Fig. 11 Comparison of C-D curves of the new (a) and current FPD (b) systems obtained with various exposure conditions.

exposure of 1 , are in agreement over the entire range of object diameter. This indicates that with an incident exposure of $\times 1 / 2$, the new system has equal low-contrast performance when compared with the current system acquired with $\times 1$ exposure. Thus, the new system could result in a dose reduction of about $50 \%$ if the lowcontrast performance needs only to be kept at the same level as the current system.

\section{Discussion}

Digital radiography using solid-state detectors commonly has been used as a recording system in various radiographic examinations. The motivation for this change includes several considerations, such as convenient archiving and display, and potential image quality advantages. Furthermore, an important characteristic of the amorphous silicon FPD radiography system is that its DQE is higher that that of both screen-film radiography and computed radiography. $\left.{ }^{8}\right)$

In this study, we investigated the physical imaging properties and C-D phantom images of a new FPD system by comparing its digital characteristic curves, presampling MTF, digital WS, and DQE with those of the current FPD system. The current FPD system was first introduced and has been widely used in many facilities, as described previously. The new FPD system had an MTF comparable to that of the current FPD system. The digital WS of the new FPD system were lower than those of the current FPD system at the same levels of incident exposure. DQE of the new FPD system was consider-

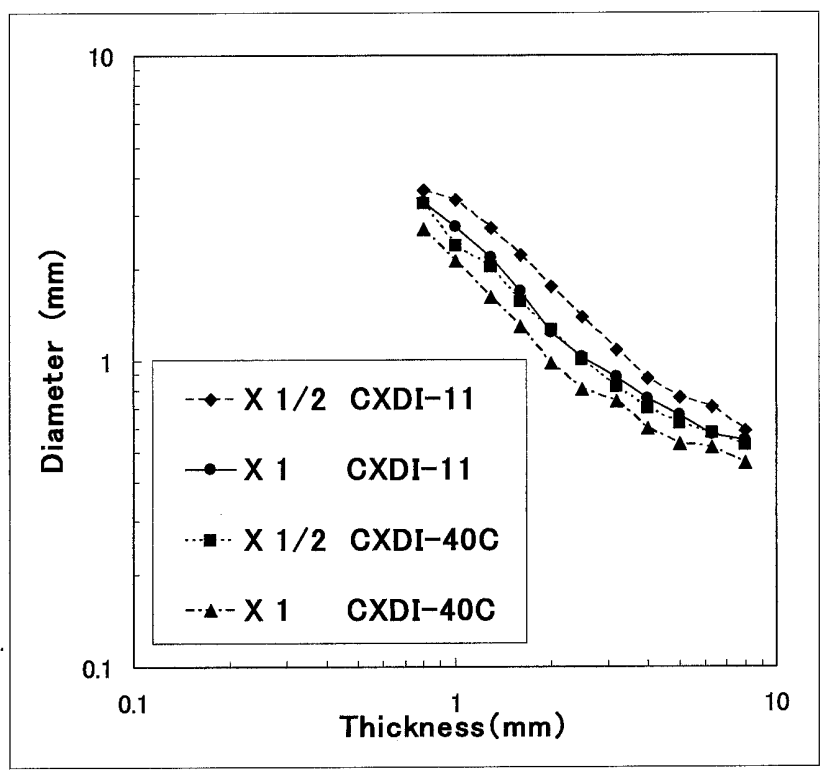

Fig. 12 Comparison of the C-D curves of the new and current FPD systems at two $(\times 1, \times 1 / 2)$ exposure conditions.

ably greater than that of the current FPD system. The average improvement of DQE at all frequencies for the new FPD system over those with the current system was about two times. These improvements were mainly accomplished by the difference in scintillator. It is well known that the signal-to-noise ratio in the radiographic image is proportional to the square root of the number of $\mathrm{x}$-ray photons used to generate the image. ${ }^{24)}$ This is due to the fact that the radiographic image is composed of the $\mathrm{x}$-ray photons, and the $\mathrm{x}$-ray photons are statisti- 
cally fluctuated. A CsI:Tl scintillator used in the new FPD system has a needle-like structure, as shown in Fig. 1. Since it can transmit fluorescent light without spreading, it can increase $\mathrm{x}$-ray absorption using a thicker layer without compromising resolution properties. For the sake of these properties, the CsI:Tl scintillator in the new FPD system is thicker(heavier) in mass thickness than the powder phosphor scintillator used in the current FPD system. Higher $\mathrm{x}$-ray absorption means that a higher fraction of $\mathrm{x}$-ray photons incident to the detector could be utilized. The higher fraction leads to a higher signalto-noise ratio, thus a lower WS could be accomplished, as shown in Fig. 7. This is the reason for the higher DQE, especially in the lower spatial frequencies, of the new FPD system.

For the higher spatial frequencies, the resolution properties of the new FPD system may contribute to the higher DQE since the MTF in the new FPD system is equivalent to that of the current FPD system despite the thicker layer, as shown in Fig. 6. However, the situation is not straightforward for the WS in the higher spatial frequencies. Lubberts described that x-rays deposited at various depths within the scintillator layer could show different amounts of spreading before they reached the surface of the detector. ${ }^{25)}$ The concept of this idea is shown in Fig. 13, namely, that $x$-rays with identical energy would give different point spread functions (PSFs) depending on the deposition depths. This phenomenon suggests that a detection process at the scintillator could cause the noise because $\mathrm{x}$-rays with identical energy, which should be detected identically, would be detected differently. This would affect the propagation of signal and noise differently. The former is characterized as MTF and computed using an average of PSF from each layer, whereas the latter is characterized as a noise transfer function (NTF) and computed using a root square sum of PSF from each layer. He showed that this mechanism, now known as the Lubberts effects, or the optical Swank factor, degrades the WS as spatial frequency increases. ${ }^{26)}$ Rabbani, Shaw, and Van Metter theoretically expressed this effect as a stochastic multistage process. ${ }^{27)}$ A thicker scintillator may suffer strong WS degradation since the deposition depth varies widely as the scintillator becomes thicker. However, this was not the case in this study. This is probably due to the fact that, since the CsI:Tl scintillator with its needle-like structure acts as an optical fiber, the fluorescent light emitted near the incident surface may not spread widely when it is transferred to the

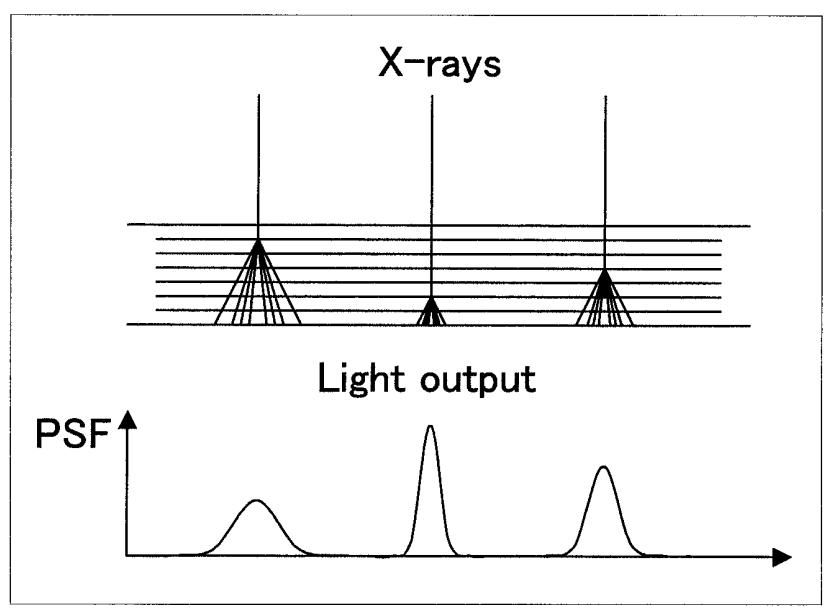

Fig. 13 Concept of different PSFs depending on the deposition depths of $\mathrm{x}$-ray energy in the scintillator.

surface of the detector. This effect maintains the PSF variance within a limited range and suppresses WS degradation. Therefore, the DQE in the new FPD system could surpass that of the current FPD system even in the higher frequencies.

The higher DQE would also predict improvement in the ability of a human observer to detect the object. Our C-D phantom study indicated that the new FPD system demonstrated substantially superior detection to that for the current FPD system. Alternatively, the new FPD system can reduce the dosage by approximately $50 \%$ while providing detectability comparable to that of the current FPD system. This result is coincident to the estimation in the DQE study. Although the beam qualities used for the DQE study $(80 \mathrm{kV}$ with $20 \mathrm{~mm} \mathrm{Al})$ and C-D phantom study (120 kV with $8 \mathrm{~cm}$ acrylic) were different, we believe that we can compare the DQE result and the C-D phantom result in the same manner, because there is no significant difference in $\mathrm{x}$-ray absorption between $80 \mathrm{kV}$ and $120 \mathrm{kV}$ for the scintillator we tested. In addition, we briefly measured the basis physical properties for $120 \mathrm{kV}$ and found that there is no remarkable difference between $80 \mathrm{kV}$ and $120 \mathrm{kV}$ in this aspect of comparison between the two systems. Therefore, although physical imaging properties cannot be directly related to expected observer performance in a diagnostic setting, in this study, there was good agreement that a higher DQE is indicative of superior image quality.

\section{Conclusion}

The newly developed FPD (CXDI-40C; CsI:T1) digi- 
tal radiography system provides radiographic images with excellent inherent physical image quality (WS and DQE) and low-contrast performance. More importantly, the new FPD system provided an approximately $50 \%$ reduction of exposure while providing comparable detection of a low-contrast object. These results agreed well with the magnitude of improvement of DQE of the new system compared with that of the current system.

\section{References}

1) Yamazaki T, Nakano $Y$, Morishita $M$, et al.: Evaluation of a newly developed digital radiography system. Radiology, 205 (P) , 9617,(1997).

2) Lee DL, Cheung LK, Rodricks B, et al.: Improved imaging performance of a $14 \times 17$-inch direct radiography system using Se/TFT detector. Proc SPIE, 3336, 14-23,(1998).

3) Chaussat C, Chabbal J, Ducourant T, et al.: New CsI/a-Si 17 " $\times 17$ " $\mathrm{x}$-ray flat panel detector provides superior detectivity and immediate direct digital output for general radiography systems. Proc SPIE, 3336, 45-57, (1998).

4) Tsukamoto A, Yamada S, Tomosaki T, et al.: Development of a selenium-based flat-panel detector for real-time radiography and fluoroscopy. Proc SPIE, 3336, 388-395, (1998).

5) Kameshima T, Kaifu N, Takimi E, et al.: Novel large area MIS-type $\mathrm{x}$-ray image sensor for digital radiography. Proc SPIE, 3336, 453-462, (1998)

6) Granfors PR, and Aufrichtig R: Performance of a $41 \times 41-\mathrm{cm}^{2}$ amorphous silicon flat panel $\mathrm{x}$-ray detector for radiographic imaging applications. Med Phys, 27, 1324-1331,(2000).

7) Watanabe M, Mochizuki C, Kameshima T, et al.: Development and evaluation of a portable amorphous silicon flat panel x-ray detector. Proc SPIE, 4320, 103-114,(2001).

8) Floyd CE Jr, Warp RJ, Dobbins JT III, et al.: Imaging characteristics of an amorphous silicon flat-panel detector for digital chest radiography. Radiology, 218, 683-688,(2001)

9) Rong XJ, Shaw CC, Liu X, et al.: Comparison of an amorphous silicon/cesium iodide flat-panel digital chest radiography system with screen/film and computed radiography systems-A contrast-detail phantom study. Med Phys, 28, 2328-2335, (2001).

10) Samei E, and Flynn MJ: An experimental comparison of detector performance for direct and indirect digital radiography systems. Med Phys, 30, 608-622,(2003)

11) Samei E: Image quality in two phosphor-based flat panel digital radiographic detectors. Med Phys, 30, 1747-1757,(2003).

12) Yamazaki T, Tamura T, Nokita M, et al:: Performance of a novel 43-cm $\times 43-\mathrm{cm}$ flat-panel detector with CsI:Tl scintillator. Proc SPIE, 5368, 379-385,(2004).

13) Yamazaki $T$, Nokita M, Hayashida $S$, et al.: A method to measure the presampling MTF using a novel edge test device and algorithm. Proc SPIE, 5368, 696-704,(2004).

14) IEC62220-1: Medical electrical equipment-Characteristics of digital X-ray imaging devices-Part 1: Determination of the detective quantum efficiency, ed 1,(2003).

15) Doi K, Kodera Y, Loo L-N, et al.: MTF's and Wiener spectra of radiographic screen-film systems volume 2 . HHS Publication FDA 86-8257,(1986).

16) Cunningham IA, and Reid BK: Signal and noise in modulation transfer function determinations using the slit, wire and edge techniques. Med Phys, 19, 1037-1044, (1992).

17) Samei E, Flynn MJ, and Reimann DA: A method for measuring the presampled MTF of digital radiographic systems using an edge test device. Med Phys, 25, 102-113, (1998).

18) Greer PB, and van Doorn T: Evaluation of an algorithm for the assessment of the MTF using an edge method. Med Phys, 27, 2048-2059, (2000).

19) Buhr E, Günther-Kohfahl S, and Neitzel U: Accuracy of a simple method for deriving the presampled modulation transfer function of a digital radiographic system from an edge image. Med Phys, 30, 2323-2331,(2003).

20) Matsumoto M, Yamamoto A, Honda I, et al.: Direct measurement of mammographic X-ray spectra using a CdZnTe detector. Med Phys, 27, 1490-1502,(2000).

21) Matsumoto M, Maeda K, Taniguchi A, et al.: Measurement of diagnostic $\mathrm{x}$-ray spectra using a high resolution Schottky CdTe detector. KEK Proc 2003-8, 46-56, (2003).

22) Loo L-N-D, Doi K, Ishida M, et al.: An empirical investigation of variability in contrast-detail diagram measurements. Proc SPIE, 419, 68-76, (1983).

23) Aufrichtig R: Comparison of low contrast detectability between a digital amorphous silicon and a screen-film based imaging system for thoracic radiography. Med Phys, 26, 1349. 1358, (1999).

24) Ter-Pogossan MM: The physical aspects of diagnostic radiology. Hoeber Medical Division, Harper \& Row, Publishers, (1967).

25) Lubberts G: Random noise produced by x-ray fluorescent screens. J Opt Soc Am, 58, 1475-1483,(1968).

26) Beutel J, Kundel HL, and Van Metter RL ed.: Handbook of medical imaging, vol.1. Physics and psycholphysics. SPIE, (2000).

27) Rabbani M, Shaw R, and Van Metter R: Detective quantum efficiency of imaging systems with amplifying and scattering mechanisms. J Opt Soc Am, A4, 895-901, (1987). 
Fig. 1 (a) 新FPD (CXDI-40C)の外観と (b)CsI:T1シンチレータの顕微鏡写真 (SEM：×1000倍)

Fig. 2 オフセットとゲイン補正のための線形原画像前処理(後処理は除く)

Fig. 3 MTFs測定のためのタングステンエッジの実験配置

Fig. $420 \mathrm{~mm}$ Alフィルタと $0.1 \mathrm{~mm} \phi$ のWピンホールコリメータで測定した光子数スペクトル $(\mathrm{FDD}=3.6 \mathrm{~m}, 80 \mathrm{kV}, 320 \mathrm{~mA}, 10 \mathrm{~s})$

Fig. 5 新FPD (CXDI-40C) と既存のFPD (CXDI-11)のディジタル特性曲線の比較

Fig. 6 新FPD と既存のFPDのプリサンプリングMTFsの比較 ここでは, 水平方向と垂直方向のプリサンプリングMTFに差がないので，水平方向だけを示す.

Fig. 7 いろいろな照射線量で測定した新FPD (a) と既存のFPD (b)のディジタルWSの比較 ここでは, 水平方向と垂直方向のディジタルWSに差がないので，水平方向だけを示す．IEC62220-1に従って，WSはナイ キスト周波数 (3.125cycles $/ \mathrm{mm})$ 以下を示す.

Fig. 8 新FPD と既存のFPDのDQEsの比較 ここでは, 水平方向と垂直方向のDQEに差がないので, 水平方向だけを示す。 IEC62220-1に従って, DQEはナイキスト周 波数 $(3.125 \mathrm{cycles} / \mathrm{mm})$ 以下を示す.

Fig. 9 新FPDと既存のFPDを用いて撮影した検出能を評価するために使用したC-Dファントム画像の比較 新FPD $(a)$ と既存のFPD $(b)$ の検出器への入射線量は同じである。

Fig. 10 C-Dファントム画像の拡大部分の比較 新FPD (左上と左下の図) と既存FPD (右上と右下の図)の画像. 新FPD と既存のFPD 検出器への相対入射線量は上と下の図 でそれぞれ 1 と 0.5 である。

Fig. 11 いろいろな照射線量で測定した新FPD (a) と既存のFPD (b)のC-D曲線の比較

Fig. 122 種類 $(\times 1, \times 1 / 2)$ の照射線量で測定した新FPDと既存のFPDのC-D曲線の比較

Fig. 13 シンチレータのいろいろな深さでX線がエネルギーを付与したときの点像分布関数の概念図

Table 新しいFPDシステムと既存のFPDシステムの仕様 